\title{
Microsatellite Stable
}

National Cancer Institute

\section{Source}

National Cancer Institute. Microsatellite Stable. NCI Thesaurus. Code C131459.

Indicates that no positive loci have been detected in the microsatellite instability (MSI) biomarkers in a sample. 